\title{
26363 - 5U BOLUS OXYTOCIN AT C/SECTION IN WOMEN AT RISK OF
}

ATONY

\section{Kylie King MBBS, Joanne Douglas, MD; Waldemar Unger, MD; Areta Wong, BC Women's Hospital, Vancouver, BC, Canada}

INTRODUCTION: Oxytocin is used routinely during cesarean section $(\mathrm{C} / \mathrm{S})$ to prevent post-partum hemorrhage (PPH) from uterine hypotonia. Some anesthesiologists and obstetricians believe that a bolus of oxytocin is more effective than infusion. Concern over bolus side-effects has led to recommendations of " 5 units by slow intravenous injection" [1]. One study found a high dose oxytocin infusion was effective compared with a low dose infusion in decreasing the need for additional uterotonics after emergent CS [2]. Bolus oxytocin versus placebo has not been previously studied at C/S. This randomized, double-blinded placebo-controlled study examines whether a 5 u oxytocin bolus reduces the need for additional uterotonics at $\mathrm{C} / \mathrm{S}$ in women at risk of uterine hypotonia.

METHODS: After ethics approval, consenting women at risk of PPH undergoing C/S were assigned to receive either $5 \mathrm{u}$ oxytocin or placebo (normal saline (NS)) over 30 secs after cord clamping. Then both groups received 40u oxytocin in $500 \mathrm{~mL}$ NS over 30 minutes, followed by $20 \mathrm{u}$ over 8 hours, ensuring that the placebo group was not disadvantaged. Primary outcome is the need for additional uterotonics. Secondary outcomes are uterine tone, estimated blood loss (EBL), side-effects including hypotension, further intervention due to hemorrhage, hemoglobin levels and time for placenta delivery. Power analysis indicated 62 subjects/group, assuming that $40 \%$ of placebo group will need more uterotonics compared with $20 \%$ in the oxytocin group (beta error 0.2, alpha error 0.05 , for a one tailed chi-squared test (p1>p2)).

RESULTS: To date, 25 subjects have been studied (Table). 13 had emergency C/S. 4 $(16 \%)$ subjects required extra oxytocin within the first hour, and another two subjects $(8 \%)$ required additional uterotonics within the first 24 hours. One required ergot as well as oxytocin. $20 \%$ had hypotension associated with the study drug ( $>20 \%$ drop in Systolic Blood Pressure). Four (16\%) had EBL $>1000 \mathrm{~mL}$, none were transfused. The code will be broken when the study is complete.

DISCUSSION: This study hopes to determine whether there are advantages in administering a bolus of oxytocin during $\mathrm{C} / \mathrm{S}$ in women at high risk of uterine hypotonia. The study was designed to ensure that there was no disadvantage to the group given the bolus of saline. If no difference is seen between the groups, women in future may be spared the increased side effects associated with a bolus while retaining the benefits of good uterine contractility.

REFERENCES:

1. Why Mothers Die 1997-1999, 135-7

2. Obstet Gynecol 2001 98:386-90 


\begin{tabular}{|l|l|}
\hline Inclusion Criteria: & \\
\hline Multiple Gestation & 9 \\
\hline$>8$ Hours oxytocin & 8 \\
\hline Macrosomia & 4 \\
\hline Past History PPH & 3 \\
\hline Posterior Previa & 1 \\
\hline Chorioamnionitis & 1 \\
\hline Polyhydramnios & 1 \\
\hline Parity >5 & 0 \\
\hline Anesthetic Technique & \\
\hline Spinal & 14 \\
\hline Epidural & 6 \\
\hline CSE & 2 \\
\hline Regional + GA & 2 \\
\hline GA & 1 \\
\hline
\end{tabular}

